\title{
About diversity and inclusion in geosciences, I think QINGQING SUN
}

Tianjin University

Presenting Author: sunqingqing17@tju.edu.cn

China is a multi-ethnic country. Han nationality accounts for $91.51 \%$ of the Chinese population. In history, only the Yuan Dynasty (Mongols) and the Qing Dynasty (Manchu) were the feudal dynasties established by ethnic minorities completely. Throughout history, national integration has made regimes more durable than complete ideological and cultural separations. Now the remarks made by foreigners on Xinjiang and Tibet (provinces where the Uygur and Tibetan ethnic groups live in concentrated communities, respectively) lose sight of China's national conditions and history.

I tried to make a questionnaire "China's ethnic minority people engaged in geosciences research" to investigate the gender, the opportunities and feelings of Chinese ethnic minorities in learning and scientific research, the number of international conferences they attended, and the number of reports they made. However, the questionnaire was refused to generate because of unknown sensitive words.

In contemporary China, a series of policies are for ethnic minority communities and ethnic minority places, including ethnic minority extra points in the college entrance examination, Western Light Project in scientific research. The program targets 12 provinces in western China, accounting for 29 percent of the country's total population, named for the graduate education of high-level minority backbone talents $(0.39 \%$ in Master's graduate students, $1 \%$ in doctorate students). I am not clear what is the resource allocation of these measures in geosciences.

The west is rich in minerals and hydropower and has carried out large-scale projects, e. g., the West-East power transmission project. However, the economy is less developed than the eastern coastal provinces. China's efforts to eradicate poverty and achieve a moderately prosperous society rely on the Rich First Pushing Those Being Rich Later. China's anti-poverty campaign has benefited from the "Internet Plus" and other emerging technologies, which adopt targeted measures and adopt multiple measures by local conditions. They are partly thanks to geosciences.

The number of newborns in China was a decline by 14.9 percent in 2020. The new regulations on the examination and approval of foreigners' permanent residence in China aroused great controversy. In the future, the importation of foreign nationalities will be a new subject in China. 